\title{
Development of a Safety Evaluation Model for Provincial Highway
}

\author{
Li Yuan, ${ }^{1}$ He-wei Yuan, ${ }^{2}$ Yong-feng $M a,{ }^{3}$ and Ying-wei Ren ${ }^{4}$ \\ ${ }^{1}$ College of Civil and Transportation Engineering, Hohai University, Nanjing 210098, China \\ ${ }^{2}$ Department of Vehicle, Henan Communication Vocational Technology College, Zhengzhou 450002, China \\ ${ }^{3}$ School of Transportation, Southeast University, Nanjing 210096, China \\ ${ }^{4}$ College of Civil Engineering and Architecture, Shan Dong University of Science and Technology, Qingdao 266510, China
}

Correspondence should be addressed to Li Yuan; yuanlibox@sina.com

Received 10 November 2013; Revised 22 December 2013; Accepted 24 December 2013; Published 8 January 2014

Academic Editor: Wuhong Wang

Copyright (C) $2014 \mathrm{Li}$ Yuan et al. This is an open access article distributed under the Creative Commons Attribution License, which permits unrestricted use, distribution, and reproduction in any medium, provided the original work is properly cited.

\begin{abstract}
Provincial highway safety is one of the most important issues in transportation. To evaluate or assess the safety performance of provincial highway, traffic crash analysis or traffic conflict analysis has been used for a long history. However, it is very difficult and time-consuming to obtain historical crash data or traffic conflict data. This study analyzes the provincial highways' accident data during 2006-2010, and the characteristics of provincial highway have been investigated; in addition the influencing elements are identified. A comprehensive approach is introduced to evaluate provincial highway safety performance and corresponding models are developed considering the accidents, geometrics, facilities, and traffic environment. The approach will also result in a safety index to indicate the safety performance level of the provincial highway. In this paper, the approach (called safety evaluation approach) is practically applied to evaluate the safety performance of some provincial highways in Hebei Province. Results from the real application indicate that the approach has good applicability and can be used by field safety engineers.
\end{abstract}

\section{Introduction}

Road safety has become a priority field worldwide and one of the major factors describing the state of the transport system with its positive and negative changes [1], especially provincial highway safety, which is one of the most important issues to be resolved by traffic engineers. According to past statistics, in China, about 32\% of traffic crashes and 34\% of fatal traffic crashes happen on the provincial highway [2]. These statistical data indicate that provincial highway is the place of significant safety concerns. There is a need to have a practically feasible way to evaluate provincial highway safety performance specifically.

In order to improve highway traffic safety performance, many research studies have been done. The most popular methods to analyze traffic safety performance are based on traffic crash analysis methods, such as crash frequency, crash rate, crash severity, and crash statistic models [3, 4]. However, all these crash-based analyses are based on past historical crash data. Accumulating crash data could be a problem to many researchers, mainly due to the difficulty to obtain these data and the reliability of past crash data [5]. For example, to determine the black spots with high traffic crash rates in China, it usually needs to take about 3 to 10 years to accumulate traffic crash data. In fact, within the time period, land use situation could change, resulting in biased safety improvement decisions.

With such considerations, noncrash-based analysis methods have been used by many researchers [6]. One of the methods is traffic conflict analysis (TCA) [7]. Based on the definition from Perkins, a traffic conflict is defined as the interactions between vehicles and such interactions would result in some actions, such as braking and movement direction change [8]. TCA methods generally cover conflicting points, number of conflicts, conflict rate, conflict distribution, and conflict forecasting models $[9,10]$. This method has been used by many researchers to analyze traffic safety 
performance. For example, in USA, TCA has been used to evaluate roadway intersection traffic safety. In Britain, TCA has been used to evaluate the impacts of safety improvement countermeasures. In Sweden, TCA is used to evaluate safety performance of high-speed highways and corresponding safety countermeasures. Besides, TCA has been widely used in Japan and Austria. In China, Lu et al. [11] have taken the weighted sum of the crossing point numbers of ideal movement trajectories as the basic conflict model for the safety level evaluation of highway intersections. In this model, the physical conditions are used to assess safety levels without the need for crash data. However, it is still hindered by some limitations for signalized intersection. Zhou et al. [12] established a conflict hazardous assessment model (CHAM) for the evaluation of urban intersection safety incorporating factors such as conflict types, conflict angles, velocity, and weight; this model is mainly used for urban intersections. In recent years, traffic conflict simulation models have been attempted to analyze traffic safety performance at roadway intersections [13, 14]. Traffic conflict simulation model development needs long-term data accumulation and simulation model parameters could change as environmental conditions change. In addition, the judgment and determination of traffic conflicts are more subjective nature. Different observers may give different traffic conflict judgments. This limits its applicability in real situation [15].

As discussed above, both crash-based and conflict-based safety analysis methods have some limitations in real applications. Highway safety evaluation is not implemented on a systematic and integrated appraisal method but simply selects a spot or section chosen by accident or conflict. The method could miss the possible accident causation by typical road condition and various traffic characteristics. Even though the traffic accident did not occur on a certain road during past few years, still it is possible to occur on that road in the near feature.

To maximize traffic safety improvement project, in the research, another approach called safety evaluation model is attempted. This approach is a comprehensive evaluation method based on accidents, geometrics, facilities, and traffic environment. With such characteristics, this approach could give a real evaluation to provincial highway safety performance. Particularly, the type of method has advantages, such as low cost, high efficiency, and less time-consuming. Furthermore, this approach can be better used by field safety engineers to find potential safety problems and corresponding countermeasures can be implemented so that possible traffic safety problems can be prevented. To develop the model, the related data of 40 provincial highway (total $4,100 \mathrm{Km}$ as of years of 2010-2012) and accident data (years of 2006-2010: 3 years) in China are collected.

\section{Approach}

The first step was getting a group of the accident features of the region through the analysis on general status and accidents. Elements for evaluating hazardous highways were collected through investigating documents from in and out

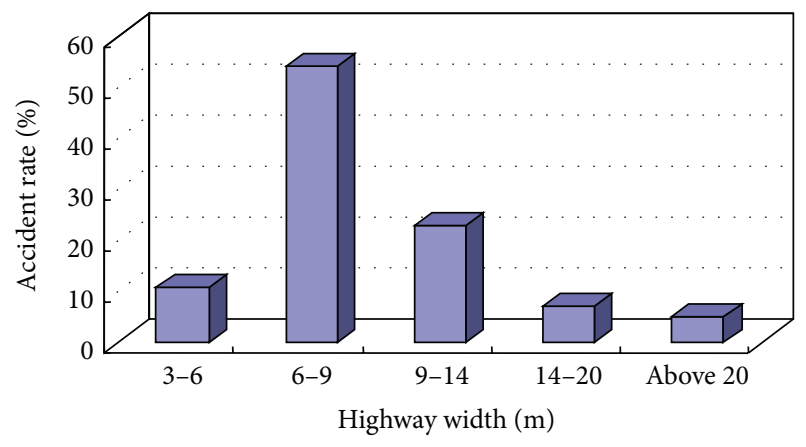

FIGURE 1: Ratio of accidents according to highway width.

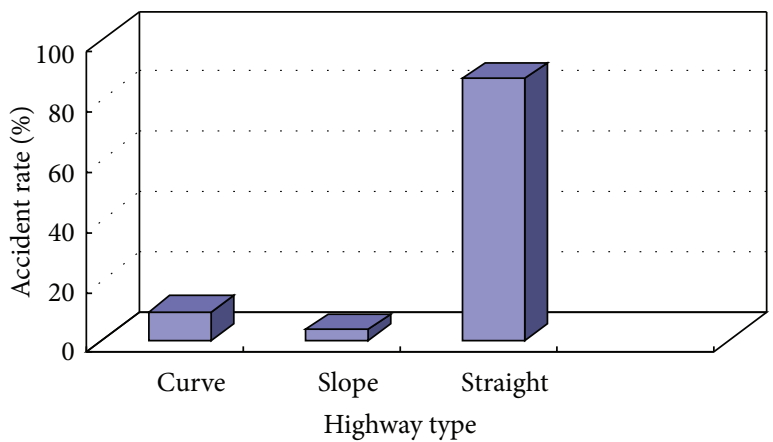

FIgURE 2: Ratio of accidents according to highway type.

of the country. Then through AHP (analysis of hierarchy process) method, relative weight of collected elements was calculated. Based on the evaluation model through this process, the hazardous highway selection criteria and scoring method were prepared.

2.1. Analysis on Accidents in Provincial Highways. Among the accident data provided by the Police Agency, only the data happening on the provincial highways (years of 20062010) were collected to analyze the features of accidents. Analyzed accident features were used as variables for provincial highway evaluation index along with collected geometrical features and environmental factors through the literature study.

2.1.1. Accident Feature according to Geometrical Structures of a Highway. As a result of comparing accident rates in provincial highway with width of the highway, it was shown that the accidents occur most frequently in highways having 6-9 m width. It shows that the alignment and safety facilities are relatively inappropriate when the width of highway is narrow, as shown in Figure 1.

In terms of the accident rate according to highway type, highway had high accident rate in a straight section with long expansion length (shown in Figure 2). However, the fatal rate compared to accident case was relatively higher in the curve and slope sections, as shown in Figure 3, proving that curve and slope sections have higher risk than straight section. 


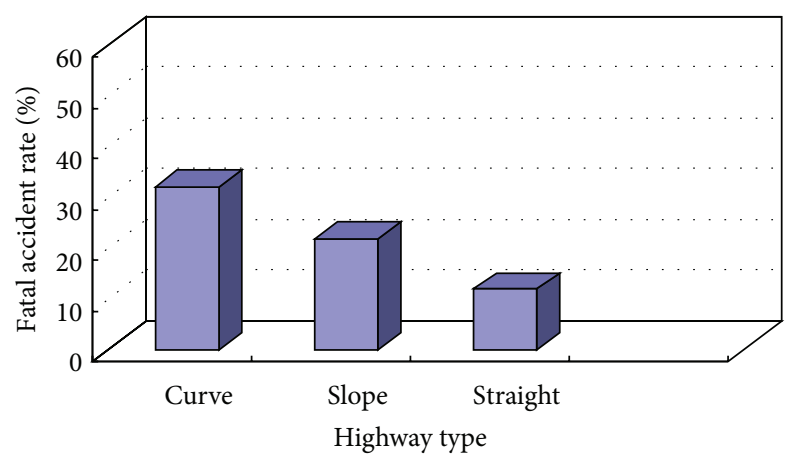

FIgURE 3: Fatal rate according to highway type.

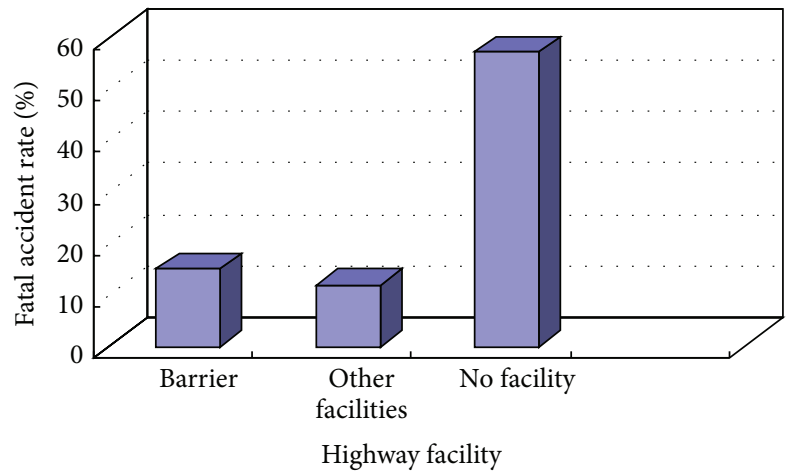

FIGURE 4: Fatal rate according to highway traffic facility.

2.1.2. Accident Feature according to Traffic Facilities of a Highway. In terms of the fatal accident rate according to the highway traffic facilities, these sections with no traffic facilities had higher risk, as shown in Figure 4, proving that no-facilities section is in serious condition.

2.1.3. Accident Feature according to Accident Types. In terms of the fatal accident rate of vehicle to pedestrian, vehicle/vehicle and single vehicle accidents, as shown in Figure 5, the order of accident types is vehicle, to pedestrian, vehicle/vehicle, and single vehicle accident, proving how the walking environment in provincial highways is in serious condition.

2.1.4. Results of Analysis. Accidents and highway features of provincial highways through the analysis are as follows: (1) the ratio of accident occurring in the width of the highway ranks highest in a width of 6-9 m; (2) provincial highways have higher fatal rate in curve and slope sections compared to straight section; (3) the order of fatal rate in provincial highway was proven to be vehicle to pedestrian, vehicle/vehicle, and single vehicle accident.

2.2. Contributing Factors to Provincial Highway Safety. There are many factors that could affect provincial highway safety performance, including subjective factors and objective factors. Subjective factors mainly refer to human-related factors such as driving behavior. Objective factors are mainly related

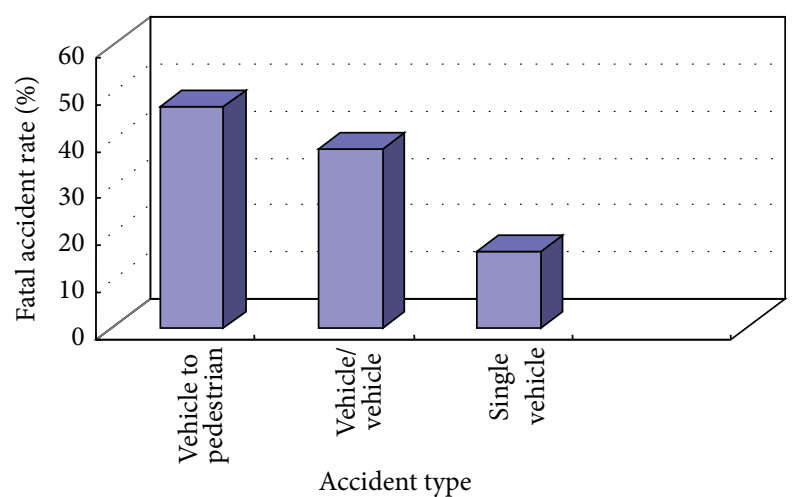

FIgURE 5: Fatal rate according to highway accident type.

to the physical characteristics of highway, such as geometrics, traffic signs and markers, and traffic characteristics. In real applications, it is hard to measure subjective factors. Thus, only objective factors are considered in developing models for safety evaluation.

According to the past research, including analysis accident feature of provincial highway, conference survey, focus group discussion, field observations, and letter survey, the major contributing factors include accident severity, geometric feature (horizontal curve, sight distance, longitudinal slope, width of the highway, and shoulder), traffic facilities (traffic signs and marking, guiding facilities, and safety facilities), traffic environment (traffic volume and configuration, crosswalk).

\section{Methodology}

As stated previously, provincial highway safety evaluation should be not only based on accident severity but also based on geometric feature, traffic facility, and traffic environment. Before the final model specifications were decided, statistical analysis (such as principle component analysis) was performed to identify significant variables for the models. All the variables included in the models (shown in Figure 6) were significant. Some variables such as lighting condition and parking, were not included in the models due to the insignificance.

\section{Evaluation Modeling Procedure}

As discussed previously, to evaluate provincial highway safety evaluation, quantified indices are needed. As seen in Figure 6, the main indices for geometric feature $\left(F_{2}\right)$, traffic facility $\left(F_{3}\right)$, and traffic environment $\left(F_{4}\right)$ are horizontal curve $\left(F_{21}\right)$, sight distance $\left(F_{22}\right)$, longitudinal slope $\left(F_{23}\right)$, lane width $\left(F_{24}\right)$, shoulder width $\left(F_{25}\right)$, traffic sign $\left(F_{31}\right)$, traffic marking $\left(F_{32}\right)$, guiding facility $\left(F_{33}\right)$, safety facility $\left(F_{34}\right)$, crosswalk $\left(F_{41}\right)$, traffic volume $\left(F_{42}\right)$, and heavy vehicle ratio $\left(F_{43}\right)$, respectively. Conceptually, each area (geometric, traffic facility, and traffic environment) should have a summarized index to quantify the safety of provincial highway in the corresponding area. This summarized index could be a linearly weighted 


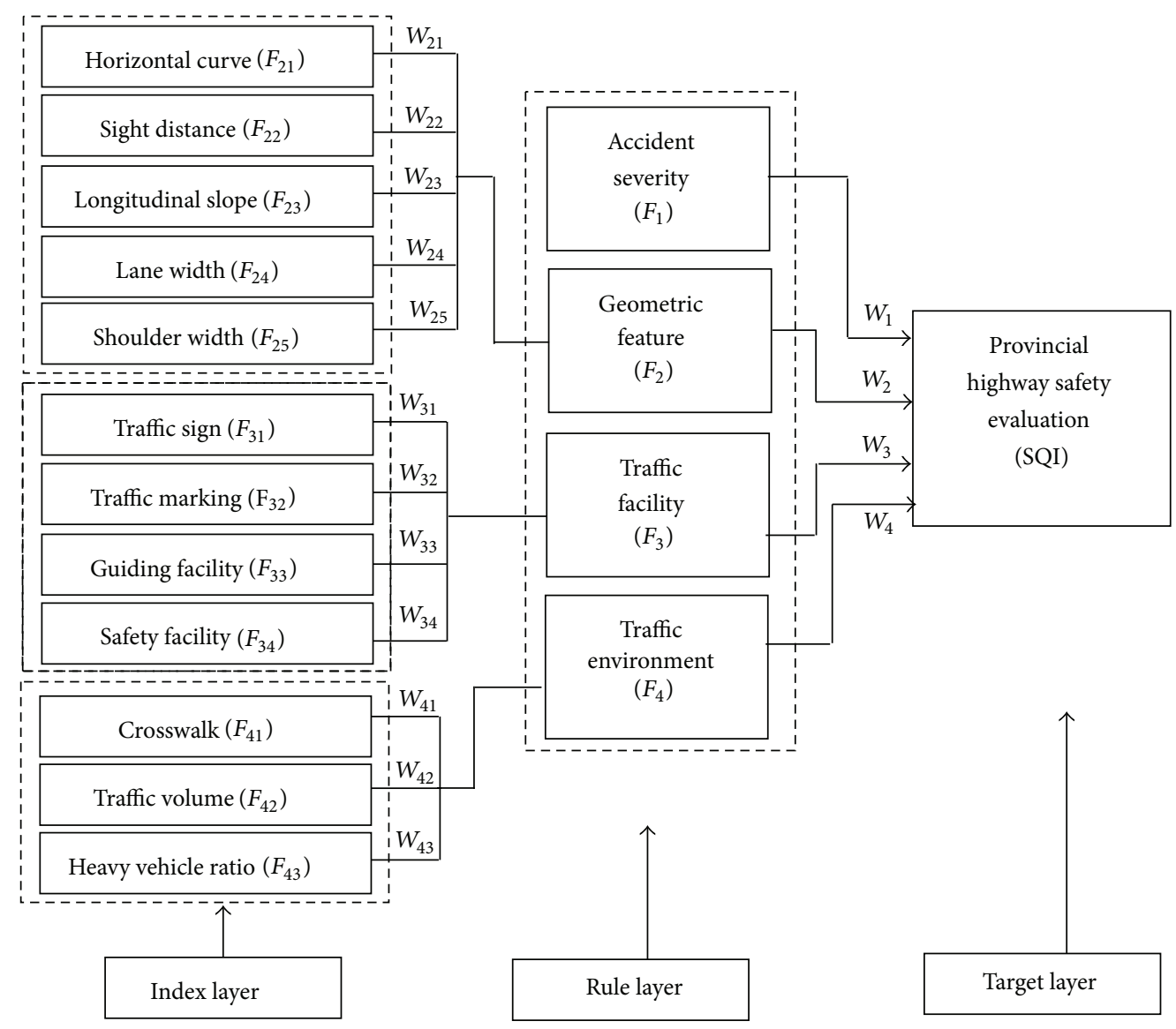

FIGURE 6: Logic structure for provincial highway safety evaluation.

combination of safety evaluation. According to Figure 6, the following equations could be used:

$$
\begin{gathered}
F_{2}=W_{21} F_{21}+W_{22} F_{22}+W_{23} F_{23}+W_{24} F_{24}+W_{25} F_{25}, \\
F_{3}=W_{31} F_{31}+W_{32} F_{32}+W_{33} F_{33}+W_{34} F_{34}, \\
F_{4}=W_{41} F_{41}+W_{42} F_{42}+W_{43} F_{43},
\end{gathered}
$$

where $F_{2}, F_{3}$, and $F_{4}$ are summary indices for geometric feature, traffic facility, traffic environment, respectively, and $W_{i j}(i=2,3,4$, and $j=1,2,3,4,5)$ are corresponding weights to be estimated through the modeling procedure.

To evaluate the overall safety performance $(F)$ of the provincial highway, $F_{1}, F_{2}, F_{3}$, and $F_{4}$ should also be linearly combined with weights $W_{1}, W_{2}, W_{3}$, and $W_{4}$.

Consider

$$
F=W_{1} F_{1}+W_{2} F_{2}+W_{3} F_{3}+W_{4} F_{4},
$$

where $F$ is the index which quantifies the overall safety performance (quality) of the provincial highway.

4.1. Determination of Index Weights. To calibrate the models shown in (1) to (2), AHP method was used to determine weights. It is not only to be applied but also to be widely used in decision-making process of public and official areas because of its accurate theoretical evidence. Prior to performing AHP method, a survey was conducted on 32 experts, including researchers who have experts in the relevant areas, transportation engineers working in the similar areas, traffic police officers, and roadway motorized vehicle users. Many of the interviewees had experienced traffic conflicts either as a driver or as a vulnerable user. People involved in the survey were required to fill a survey form to give a rating of the importance of each variable as relative to other variables, independently. Detailed explanations were presented before the forms were completed. After all the survey forms were completed, the AHP method was used to obtain the weights included in (1) to (2).

4.1.1. Weights of Rule Layer. Using AHP method, the weight of accident severity, geometric features, traffic facility, and traffic environment had been calculated. Table 1 is the result of calculating the weight for evaluators.

Geometric mean and weight about accident severity can be computed as follows.

(i) Geometric Mean $=(1 \times 2 \times 3 \times 5)^{(1 / 4)}=2.34$.

(ii) Weight $=2.34 / 4.91=0.47$.

Similar to analysis mentioned above, values of other geometric means and weights are shown in Table 1. 
TABLE 1: Result of calculating the weight for evaluators.

\begin{tabular}{lcccccc}
\hline & Accident severity & Geometric feature & Traffic facility & Traffic environment & Geometric mean & Weight \\
\hline Accident severity & 1 & 2 & 3 & 5 & 4 & 2.34 \\
Geometric feature & 0.5 & 1 & 2 & 1 & 2 & 1.41 \\
Traffic facility & 0.3333 & 0.5 & 0.5 & 1 & 0.77 \\
Traffic environment & 0.2 & 0.25 & - & - & 0.28 \\
Sums & - & - & & 0.15 & 4.91 \\
\hline
\end{tabular}

TABLE 2: Result of calculating constancy index of evaluators.

\begin{tabular}{|c|c|c|c|c|c|c|}
\hline & Accident severity & Geometric feature & Traffic facility & Traffic environment & Row sum & Row sum/weight \\
\hline Accident severity & 0.47 & 0.56 & 0.45 & 0.5 & 1.98 & 4.16 \\
\hline Geometric feature & 0.28 & 0.28 & 0.3 & 0.4 & 1.26 & 4.38 \\
\hline Traffic facility & 0.15 & 0.14 & 0.15 & 0.2 & 0.64 & 4.14 \\
\hline Traffic environment & 0.09 & 0.08 & 0.07 & 0.1 & 0.34 & 4.2 \\
\hline Sums & - & - & - & - & - & 16.9 \\
\hline
\end{tabular}

4.1.2. Test AHP Result. To test AHP result, weights were multiplied by each column of judgment standard in the comparison table. The driven figures are summarized in Table 2. Then the sum of each column was divided into the weights of each rule layers.

After computing the means of values obtained from Table 2, consistency index had been calculated as follows.

(i) Means $=16.9 / 4=4.22$.

(ii) CI $($ Conformity $)=($ Means $-n) /(n-1)=(4.22-$ $4) /(4-1)=0.07$.

(iii) $\mathrm{CR}($ Consistency Index $)=\mathrm{CI} / \mathrm{RI}=0.07 / 0.9=0.077$,

where: RI is Random Index that can be obtained from table according to the number of factors $(n)$, and its value is 0.9 .

As a result of calculating consistency index (CR), its value is 0.077 ; when it is less than 0.1 , it is judged that the process of decision making is consistent.

Similar to analysis mentioned above, weights included in (1) to (2) are determined and summarized in Table 3. The following equation was obtained based on the AHP method:

$$
\begin{gathered}
F_{2}=0.23 F_{21}+0.21 F_{22}+0.31 F_{23}+0.13 F_{24}+0.12 F_{25}, \\
F_{3}=0.3 F_{31}+0.13 F_{32}+0.2 F_{33}+0.37 F_{34}, \\
F_{4}=0.32 F_{41}+0.45 F_{42}+0.23 F_{43}, \\
F=0.47 F_{1}+0.28 F_{2}+0.15 F_{3}+0.1 F_{4} .
\end{gathered}
$$

\section{Setting of Evaluation Criteria for Evaluation Index}

5.1. Evaluation Criteria of Accident Severity. Method considering the accident severity is applied by calculating the index "traffic accident." Traffic accident index is calculated using the following equation:

$$
\begin{gathered}
A S_{i}=\left(\frac{A_{i}}{\sum_{i=1}^{n} A_{i}}+\frac{P S_{i}}{\sum_{p=1}^{n} P S_{i}}\right) \times 100 \%, \\
P S_{i}=\sum P_{j} S_{j},
\end{gathered}
$$

where $A S_{i}$ is the accident severity index, $A_{i}$ is the number of accident in $i$ section, $P S_{i}$ is the accident severity in $i$ section, $P_{j}$ is the weighting factor of person's accident, and $S_{j}$ is the number of relating person's accidents.

In case of the weighting factor, its value is added for each type of accidents by categorizing accidents with human damage into death, serious, and slight injuries. Values for adding weight were death, serious injury, and slight injury $=$ $28: 3: 1[16]$.

Accident severity index $\left(A S_{i}\right)$ calculated using (4) and (5) was summarized in an order to be scored according to the comparative evaluation for subjected sections (shown in Table 4).

\subsection{Evaluation Criteria according to Geometric Features}

5.2.1. Horizontal Curve. The risk of accident in horizontal curve has been proven through the analysis on the features of accidents on provincial highway [17]. The radius of horizontal curve in provincial highway can be installed up to $115-360 \mathrm{~m}$ according to the design speed and is scored to the relative evaluation for each subjected section. Table 5 is the radius standard according to the design speed.

Horizontal curve standard for provincial highway is general radius for ground level and min. radius for mountain level;

(i) calculation method: number of understandard radii/section lengths $(\mathrm{km})$

(ii) scoring method: the calculated value is summarized in the order to be scored by relative evaluation for each subjective section (shown in Table 6). 
TABLE 3: Weights of comprehensive evaluation on provincial highway.

\begin{tabular}{|c|c|c|c|c|c|}
\hline \multicolumn{3}{|c|}{ Rule layer } & \multicolumn{3}{|c|}{ Index layer } \\
\hline Index & $W_{i}$ & Weight & Subindex & $w_{i j}$ & Combined weight \\
\hline Accident severity & $W_{1}$ & 0.47 & & - & \\
\hline \multirow{5}{*}{ Geometric feature } & \multirow{5}{*}{$W_{2}$} & \multirow{5}{*}{0.28} & Horizontal curve & $w_{12}$ & 0.23 \\
\hline & & & Sight distance & $w_{22}$ & 0.21 \\
\hline & & & Longitudinal slope & $w_{23}$ & 0.31 \\
\hline & & & Lane width & $w_{24}$ & 0.13 \\
\hline & & & Shoulder width & $w_{25}$ & 0.12 \\
\hline \multirow{4}{*}{ Traffic facility } & \multirow{4}{*}{$W_{3}$} & \multirow{4}{*}{0.15} & Traffic sign & $w_{31}$ & 0.3 \\
\hline & & & Traffic marking & $w_{32}$ & 0.13 \\
\hline & & & Guiding facility & $w_{33}$ & 0.2 \\
\hline & & & Safety facility & $w_{34}$ & 0.37 \\
\hline \multirow{3}{*}{ Traffic environment } & \multirow{3}{*}{$W_{4}$} & \multirow{3}{*}{0.10} & Crosswalk & $w_{41}$ & 0.32 \\
\hline & & & Traffic volume & $w_{42}$ & 0.45 \\
\hline & & & Heavy vehicle ratio & $w_{43}$ & 0.23 \\
\hline
\end{tabular}

TABLE 4: Scoring method according to accident severity index $\left(A S_{i}\right)$.

\begin{tabular}{lcccc}
\hline $\begin{array}{l}\text { Relative ratio } \\
\left(A S_{\mathrm{i}}\right)\end{array}$ & Under 20\% & $20 \%-40 \%$ & $40 \%-60 \%$ & $60 \%-100 \%$ \\
\hline Score & $\leq 40$ & $\leq 60$ & $\leq 80$ & $\leq 100$ \\
\hline
\end{tabular}

TABLE 5: Radius standard for plane curve for design speed.

\begin{tabular}{lcccc}
\hline \multirow{2}{*}{ Classification } & \multirow{2}{*}{ Unit } & \multicolumn{3}{c}{ Design speed $(\mathrm{km} / \mathrm{h})$} \\
& & 100 & 80 & 60 \\
\hline Radius (general) & \multirow{2}{*}{$\mathrm{m}$} & 700 & 400 & 200 \\
Min. radius & & 360 & 220 & 115 \\
\hline
\end{tabular}

TABLE 6: Scoring method according to number of curve sections.

\begin{tabular}{lcccc}
\hline Relative ratio & Under 10\% & $10 \%-20 \%$ & $20 \%-30 \%$ & $30 \%-50 \%$ \\
\hline Score & $\leq 40$ & $\leq 60$ & $\leq 80$ & $\leq 100$ \\
\hline
\end{tabular}

TABLE 7: Minimum sight distance standard according to design speed.

\begin{tabular}{llll}
\hline Design speed $(\mathrm{km} / \mathrm{h})$ & 100 & 80 & 60 \\
\hline Sight distance $(\mathrm{m})$ & 160 & 110 & 75 \\
\hline
\end{tabular}

TABLE 8: Scoring method according to number of sight distance defect sections.

\begin{tabular}{lcccc}
\hline Relative ratio & Under 10\% & $10 \%-20 \%$ & $20 \%-30 \%$ & $30 \%-50 \%$ \\
\hline Score & $\leq 40$ & $\leq 60$ & $\leq 80$ & $\leq 100$ \\
\hline
\end{tabular}

TABLE 9: Longitudinal slope standard for design speed.

\begin{tabular}{llll}
\hline Design speed $(\mathrm{km} / \mathrm{h})$ & 100 & 80 & 60 \\
\hline Maximum longitudinal slope & $4 \%$ & $5 \%$ & $6 \%$ \\
\hline
\end{tabular}

5.2.2. Sight Distance. Sight distance defect is the major cause of accidents such as previous collision and others frequently occurring in provincial highway $[18,19]$ the score should be
TABLE 10: Scoring method according to number of longitudinal slope sections.

\begin{tabular}{lcccc}
\hline Relative ratio & Under 10\% & $10 \%-20 \%$ & $20 \%-30 \%$ & $30 \%-50 \%$ \\
\hline Score & $\leq 40$ & $\leq 60$ & $\leq 80$ & $\leq 100$ \\
\hline
\end{tabular}

TABLE 11: Scoring method according to mean lane width.

\begin{tabular}{lcccc}
\hline Lane width $(\mathrm{m})$ & $3.5-3.75$ & $3.25-3.5$ & $3-3.25$ & Under 3 \\
\hline Score & $\leq 40$ & $\leq 60$ & $\leq 80$ & $\leq 100$ \\
\hline
\end{tabular}

high if the ratio of sight distance defect section is high. Sight distance defect section refers to the standard less than the minimum sight distance standard according to the design speed (shown in Table 7);

(i) calculation method: number of sight distance defect sections/section lengths;

(ii) scoring method: the calculated value is summarized in the order to be scored by relative evaluation for each subjective section (shown in Table 8).

5.2.3. Longitudinal Slope. The risk of accident in longitudinal slope has been proven through the preceding researches. The longitudinal slope in provincial highway can be installed up to $4 \%-6 \%$ according to the design speed and is scored to the relative assessment for each subjected section. Table 9 is the maximum longitudinal slope standard according to the design speed;

(i) calculation method: number of understandard longitudinal slopes/section lengths $(\mathrm{km})$;

(ii) scoring method: the calculated value is summarized in the order to be scored by relative evaluation for each subjective section (shown in Table 10).

5.2.4. Lane Width. It has been proven that the risk of accidents is higher with narrow lane width according to the 
TABLE 12: Calculation and scoring method according to assessment items.

\begin{tabular}{|c|c|c|c|c|}
\hline Index & Subindex & Assessment element & Standard & Score \\
\hline \multirow{19}{*}{ Geometric feature $\left(F_{2}\right)$} & \multirow{4}{*}{ Horizontal curve $\left(F_{21}\right)$} & \multirow{4}{*}{ Number of curve sections (\%) } & Under 10 & $\leq 40$ \\
\hline & & & $10-20$ & $\leq 60$ \\
\hline & & & $20-30$ & $\leq 80$ \\
\hline & & & $30-50$ & $\leq 100$ \\
\hline & \multirow{4}{*}{ Sight distance $\left(F_{22}\right)$} & \multirow{4}{*}{ Number of sight distance defect sections (\%) } & Under 10 & $\leq 40$ \\
\hline & & & $10-20$ & $\leq 60$ \\
\hline & & & $20-30$ & $\leq 80$ \\
\hline & & & $30-50$ & $\leq 100$ \\
\hline & \multirow{4}{*}{ Longitudinal slop $\left(F_{23}\right)$} & \multirow{4}{*}{ Number of longitudinal slope sections (\%) } & Under 10 & $\leq 40$ \\
\hline & & & $10-20$ & $\leq 60$ \\
\hline & & & $20-30$ & $\leq 80$ \\
\hline & & & $30-50$ & $\leq 100$ \\
\hline & \multirow{4}{*}{ Lane width $\left(F_{24}\right)$} & \multirow{4}{*}{ Mean lane width (m) } & $3.5-3.75$ & $\leq 40$ \\
\hline & & & $3.25-3.5$ & $\leq 60$ \\
\hline & & & $3-3.25$ & $\leq 80$ \\
\hline & & & Under 3.25 & $\leq 100$ \\
\hline & \multirow{3}{*}{ Shoulder width $\left(F_{25}\right)$} & \multirow{3}{*}{ Mean of shoulder width (m) } & Nonpavement & 100 \\
\hline & & & $0-1.5$ & Interpolation \\
\hline & & & Above 1.5 & - \\
\hline
\end{tabular}

TABLE 13: Survey form for traffic facility.

\begin{tabular}{|c|c|c|c|}
\hline Index & Subindex & Items contributing to the rating & Score range \\
\hline \multirow{16}{*}{ Traffic facility $\left(F_{3}\right)$} & \multirow{4}{*}{ Traffic sign $\left(F_{31}\right)$} & $\begin{array}{l}\text { The installation meets the standard, good visibility, and reasonable } \\
\text { message }\end{array}$ & $\leq 40$ \\
\hline & & Poor visibility and reasonable message and installation & $\leq 60$ \\
\hline & & Worse visibility and some unseasonable message and installation & $\leq 80$ \\
\hline & & Worst visibility and most unreasonable message and installation & $\leq 100$ \\
\hline & \multirow{4}{*}{ Traffic marking $\left(F_{32}\right)$} & The installation meets the standard and good visibility & $\leq 40$ \\
\hline & & Poor visibility and reasonable installation & $\leq 60$ \\
\hline & & Worse visibility and some unseasonable installation & $\leq 80$ \\
\hline & & Worst visibility and most unreasonable installation & $\leq 100$ \\
\hline & \multirow{3}{*}{ Guiding facility $\left(F_{33}\right)$} & Spacing setting, number, and layout size satisfy standard & $\leq 40$ \\
\hline & & Spacing setting, number, and layout size basically satisfy standard & $\leq 60$ \\
\hline & & $\begin{array}{l}\text { Most spacing setting and number don not satisfy the standard. Layout } \\
\text { size is slightly smaller than the normative value. }\end{array}$ & $\leq 80$ \\
\hline & \multirow{5}{*}{ Safety facility $\left(F_{34}\right)$} & $\begin{array}{l}\text { Spacing setting and number don not satisfy the standard. Layout size } \\
\text { is less than the minimum. }\end{array}$ & $\leq 100$ \\
\hline & & Continuous safety barriers or $10 \mathrm{~m}$ safety zone & $\leq 40$ \\
\hline & & Safety barriers for hard obstacles or steep slopes within $6 \mathrm{~m}$ & $\leq 60$ \\
\hline & & $\begin{array}{l}\text { Safety barriers for more than half of hard obstacles or steep slopes } \\
\text { within } 3 \mathrm{~m}\end{array}$ & $\leq 80$ \\
\hline & & Barriers not generally used & $\leq 100$ \\
\hline
\end{tabular}

preceding researches. Therefore, more score is given to lane width narrower lane width. The lane width standard is $3.0 \mathrm{~m}-$ $3.5 \mathrm{~m}$ according to the design speed. Calculation method according to the lane width is mean lane width of subjected sections, and Table 11 is the scoring method according to mean lane width.
5.2.5. Shoulder Width. Shoulder can be used to install safety facilities or as pedestrian area, and correlation with accident had been proven by preceding researches [20]. Therefore, score is granted more at narrower shoulder width. Shoulder width under ideal of provincial highway is $1.5 \mathrm{~m}$ or more. In case of unpaved shoulders, pavement is serious matter. 
TABLE 14: Calculation and scoring method according to assessment items.

\begin{tabular}{|c|c|c|c|c|}
\hline Index & Subindex & Assessment element & Standard & Score \\
\hline \multirow{9}{*}{ Traffic environment $\left(F_{4}\right)$} & \multirow{4}{*}{ Crosswalks $\left(F_{41}\right)$} & \multirow{4}{*}{ Number of crosswalk in section/section length } & Under $10 \%$ & $\leq 40$ \\
\hline & & & $10 \%-20 \%$ & $\leq 60$ \\
\hline & & & $20 \%-30 \%$ & $\leq 80$ \\
\hline & & & Above $30 \%$ & $\leq 100$ \\
\hline & \multirow{3}{*}{ Traffic volume $\left(F_{42}\right)$} & \multirow{3}{*}{ ADT per lane } & Lower traffic & $\leq 40$ \\
\hline & & & Midtraffic & $\leq 60$ \\
\hline & & & Heavier traffic & $\leq 100$ \\
\hline & \multirow{2}{*}{ Heavy vehicle ratio $\left(F_{43}\right)$} & \multirow{2}{*}{ Heavy vehicle/traffic volume } & Below 36\% & Interpolation \\
\hline & & & Above $36 \%$ & 100 \\
\hline
\end{tabular}

TABLE 15: Definition of level of provincial highway safety.

\begin{tabular}{lccc}
\hline Level of safety & Rate & Color & Condition \\
\hline A & $\leq 40$ & Green & Very safe \\
B & $\leq 60$ & Blue & Safe \\
C & $\leq 80$ & Orange & Unsafe \\
D & $\leq 100$ & Red & Dangerous \\
\hline
\end{tabular}

Table 12 is the summary of calculation and scoring methods of each geometric feature presented above.

5.3. Evaluation Criterion of Traffic Facility. Similar to the analysis of method presented above, Table 13 is the survey form designed and revised in the research. This form provides the rating score range for each evaluation index and corresponding of traffic facility. Field surveyors need to survey the traffic facilities and fill the corresponding parts in the form. It is easy to use the form although some subjective effects could affect rating results.

\subsection{Evaluation Criterion of Traffic Environment}

5.4.1. Crosswalk. Provincial highway has high accident rate during pedestrian's crossing of the highway [21]. Therefore, considering the ratio of the crosswalk, higher score is given to higher number of crosswalks;

(i) calculation method: number of crosswalks in section/section lengths;

(ii) scoring method: Table 14 is the scoring method according to the number of crosswalks in a section.

5.4.2. Traffic Volume. Higher traffic volume refers to higher risk of accidents [22]. Therefore, highway with higher traffic volume are called hazardous highway;

(i) calculation method: using the ADT (vehicles/day) of each lane of subjected section;

(ii) scoring method: Table 14 showed the scoring method according to the volume. ADT had been calculated as shown below;

(iii) low traffic: $\mathrm{ADT}<\mu-\sigma$ of subjected section;

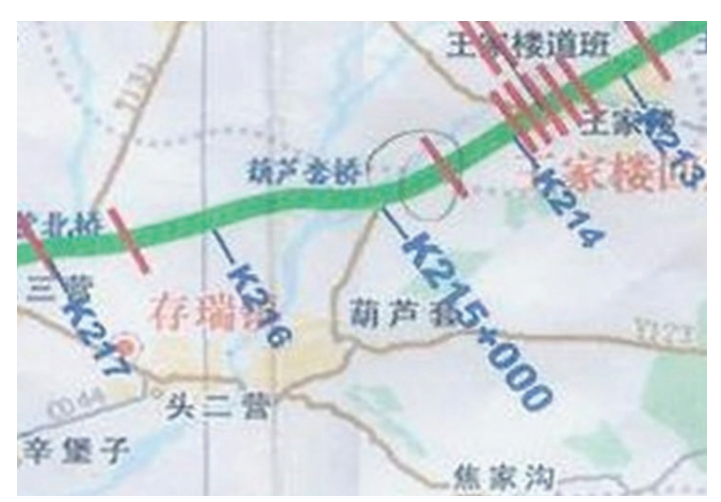

FIGURE 7: Hebei provincial highway S241 sections.

(iv) mid traffic: $\mu-\sigma<\mathrm{ADT}<\mu+\sigma$ of subjected section;

(v) heavy traffic: ADT $>\mu+\sigma$ of subjected section;

where $\mu$ is the mean $\mathrm{ADT}$ for number of lanes and $\sigma$ is the distribution.

5.4.3. Heavy Vehicle Ratio. Higher rate of heavy vehicle is known to increase the number of accidents. Therefore, higher score is given to the section with higher ratio of heavy vehicles. According to the traffic volume statistical report, the mean of daily heavy vehicle in provincial highway is $36 \%$ (shown in Table 14).

\section{Usage of Overall Safety Rating of Provincial Highway}

Safety rating in use either predicts safety outcomes for given designs or provides a retrospective assessment. For a given provincial highway, SQI value (overall rating) calculated from previous equations is used as the base for level of safety. SQI value can be classified into 4 levels from A to D with A indicating the best safety service and D the worst safety service. In order to define level of safety service, field survey activities to many provincial highways were conducted in Hebei Province, Jiangsu Province, Shandong Province, and other areas in China. Based on field survey results, the level of provincial highway safety is shown in Table 15. 
TABLE 16: Survey results of Hebei provincial highway S241 sections.

\begin{tabular}{lccc}
\hline Test section & Evaluation index & K213-k214 & K215-K216 \\
\hline & Accident severity & 70 & 5 \\
& Horizontal curve & 70 & 85 \\
Geometric feature & Sight distance & 70 & 50 \\
& Longitudinal slope & 20 & 20 \\
& Lane width & 45 & 45 \\
\hline & Shoulder width & 50 & 30 \\
Traffic facility & Traffic sign & 30 & 30 \\
& Traffic marking & 65 & 75 \\
Traffic environment & Guiding facility & 90 & 90 \\
& Safety facility & 45 & 30 \\
\hline
\end{tabular}

TABLE 17: Evaluation results of Hebei provincial highway S241 sections.

\begin{tabular}{lccccc}
\hline \multirow{2}{*}{ Test section } & & \multicolumn{2}{c}{ Evaluation rating } & & \multirow{2}{*}{ Overall rating (SQI) } \\
& Accident severity & Geometric feature & Traffic facility & Traffic environment & \\
\hline $1(\mathrm{k} 213-\mathrm{k} 214)$ & 70 & 68 & 65 & 45 & 66 \\
$2(\mathrm{k} 215-\mathrm{k} 216)$ & 5 & 52 & 65 & 46 & $\mathrm{C}^{*}$ \\
\hline
\end{tabular}

* Orange color and ${ }^{\#}$ blue color.

For the levels of $\mathrm{A}$ and $\mathrm{B}$, there is no need to propose any special improvement activities. Only regular or routine safety management will be sufficient. For the level of $\mathrm{C}$, certain adjustments and minor additions in improvement are needed. For the level of D, major adjustments in improvement are certainly needed.

\section{Case Study}

Some test provincial highway sections in Hebei Province were used for the application purpose. 1000-meter-long sections of provincial highway were shown in Figure 7, and survey scores were listed in Table 16. The results were obtained based on the criteria provided in Table 4 and Tables 12-14.

Based on model (3), the evaluation results were listed in Table 17.

It was shown that the safety level of section two is A that means the best safety service, but traffic facility of section was considered fair, indicating that it is a potential risk factor, and those of the geometric and traffic environments were considered safe. Whereby, minor safety maintenance is required. The overall results of section one illustrated that the safety level is $\mathrm{C}$ and the geometric and traffic facility safeties were poor. Therefore, section one needed middlescale improvement.

\section{Conclusions}

This research proposes a standard and safety evaluation measure for provincial highway. To provide realistic standard, the data of accidents occurring in provincial highways were analyzed to drive their features. Also by researching previous researchers, major elements were selected to evaluate provincial highway, and the weights of these elements had been calculated using AHP method.

It is judged that using the result of this research can maximize the efficacy of highway safety management project since it can select hazardous highway not only based on the number of accidents but also based on geometric feature, traffic facility, and traffic environment. Also, this research is different from the ones in the past in a way that crash-based analysis and traffic-conflict analysis were used which can be difficult to apply in real cases. On the contrary, this research had made it easy to apply site application.

With models developed in the research project, provincial highway engineers are able to better or more objectively evaluate safety performance so that optimized improvement options could be planned. However, in order to reasonably use the evaluation models, the models should be upgraded on the yearly basis with the new field data collected. In fact, the approach described in the paper can be implemented into a computer-based package with friendly software interfaces. Field engineers can use the computer-based package to perform field surveys and enter data to the package. This can reduce significant amount of time to process the survey results and make the survey work much easier.

\section{Conflict of Interests}

The authors declare that there is no conflict of interests regarding the publication of this paper. 


\section{Acknowledgment}

This research was supported in part by the National Natural Science Foundation of China with nos. 51308192 and 51208100. The authors would like to show great appreciation for these supports.

\section{References}

[1] G. Dell'Acqua and M. Busiello, "Safety data analysis to evaluate highway alignment consisitency," Transportation Research Record, no. 2349, pp. 121-128, 2013.

[2] F. Q. Pan, L. X. Zhang, and J. Lu, "A method for determining the number of traffic conflict points between vehicles at majorminor highway intersections," Traffic Injury Prevention, vol. 14, no. 4, pp. 424-433, 2013.

[3] S. Danief and R. Edward, "Variability in rural accident reporting," Journal of the Transportation Research Board, no. 910, pp. 8-13, 1983.

[4] M. Wu and C. Z. Wu, "Methods to improve the plain terrain expanded freeway under accident reason analysis," Journal of Transport Information and Safety, vol. 29, no. 6, pp. 73-77, 2011.

[5] A. Joaquin, L. Griselda, and D. O. Juan, "Analysis of traffic accident severity using decision rules via decision trees," Expert Systems with Application, vol. 40, no. 15, pp. 6047-6054, 2013.

[6] B. Son, M. Park, and S. Lee, "A study for hazardous road selection criteria for provincial roads," Journal of the Eastern Asia Society for Transportation Studies, vol. 6, pp. 3426-3440, 2005.

[7] L. Yuan and J. Lu, "Safety evaluation and improvements for highway intersections," Journal of the Transportation Research Board, no. 2060, pp. 46-52, 2008.

[8] S. R. Perkins, "Traffic conflict characteristics-accident potential at intersections," Highway Research Record 225, HRB, National Research Council, Washington, DC, USA, 1968.

[9] J. J. Lu, Q. J. Xiang, and S. Dissanayake, “The ways to improve highway safety," Journal of Advances in Transportation Studies, vol. 2, pp. 3-14, 2004.

[10] G. Davis, J. Hourdos, and H. Xiong, "Outline of a causal theory of traffic conflicts and collisions," in Proceedings of the 87th Annual Meeting, Washington, DC, USA, 2008.

[11] J. Lu, F. Q. Pan, and Q. J. Xiang, "Level-of-safety service for safety performance evaluation of highway intersections," Journal of the Transportation Research Board, no. 2075, pp. 2433, 2008.

[12] S. Zhou, J. Sun, X. An, and K. P. Li, "The development of a conflict hazardous assessment model for evaluating urban intersection safety," Transport, vol. 26, no. 2, pp. 216-223, 2011.

[13] H. E. Ross, D. L. Sicking, and R. A. Zimmer, "Recommended procedures for the safety performance evaluation of highway features," NCHRP Report 350, TRB, National Research Council, Washington, DC, USA, 1993.

[14] F. Huang and P. Liu, "Identifying if VISSIM simulation model and SSAM provide reasonable estimates for field measured traffic conflicts at signalized intersections," Accident Analysis and Prevention, vol. 50, pp. 1014-1024, 2012.

[15] P. Margie, S. Richard, and S. David, "World report on road traffic injury prevention," Report, World Health Organization, Geneva, Switzerland, 2004.

[16] K. F. Wu and E. T. Donnell, "Exploring the association between traffic safety and geometric design consistency based on vehicle speed metrics," Journal of Transportation Engineering, vol. 139, no. 7, pp. 738-748, 2013.

[17] F. J. Camacho-Torregrosa, A. M. Pérez-Zuriaga, J. M. CampoyUngría, and A. García-García, "New geometric design consistency model based on operating speed profiles for road safety evaluation," Accident Analysis and Prevention, vol. 61, pp. 33-42, 2013.

[18] N. Roussiamanis, A. Kaltsounis, and S. Vardaki, "A review of stopping sight distance in road guidelines," Proceedings of the Institution of Civil Engineers: Transport, vol. 166, no. 5, pp. 305312, 2013.

[19] S. E. Ibrahim, T. Sayed, and K. Ismail, "Methodology for safety optimization of highway cross-sections for horizontal curves with restricted sight distance," Accident Analysis and Prevention, vol. 49, pp. 476-485, 2012.

[20] Z. Z. Li, K. Kepaptsoglou, and Y. Lee, "Safety effects of shoulder paving for rural and urban interstate, multilane, and two-lane highways," Journal of Transportation Engineering, vol. 139, no. 10, pp. 1010-1019, 2013.

[21] C. Havard and A. Willis, "Effects of installing a marked crosswalk on road crossing behaviour and perceptions of the environment," Transportation Research F, vol. 15, no. 3, pp. 249260, 2012.

[22] D. Stavrinos, J. L. Jones, and A. A. Garner, "Impact of distracted driving no safety and traffic flow," Accident Analysis and Prevention, vol. 61, pp. 63-70, 2013. 


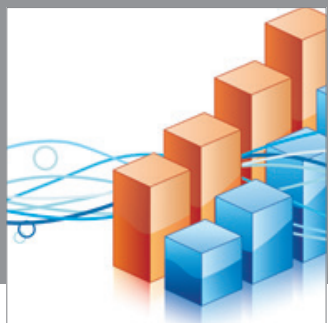

Advances in

Operations Research

mansans

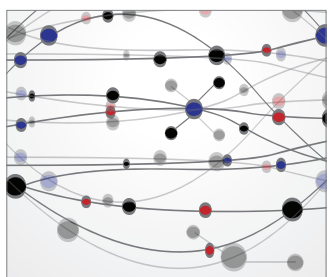

The Scientific World Journal
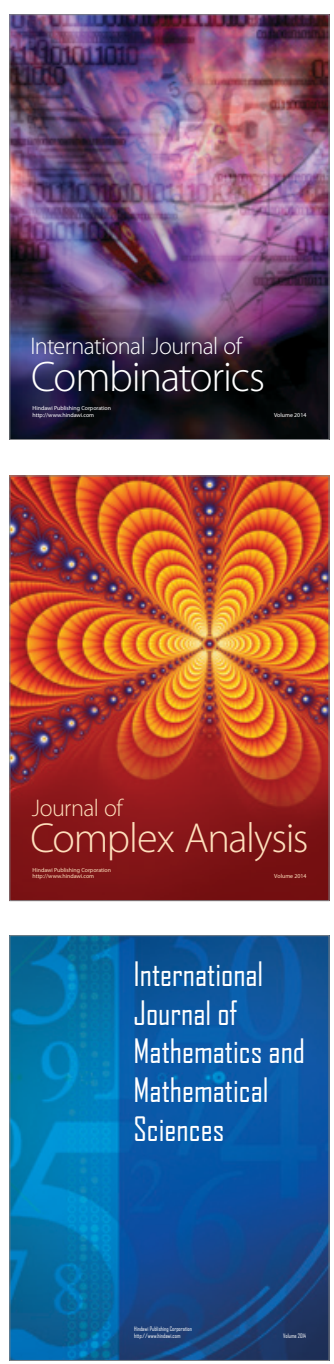
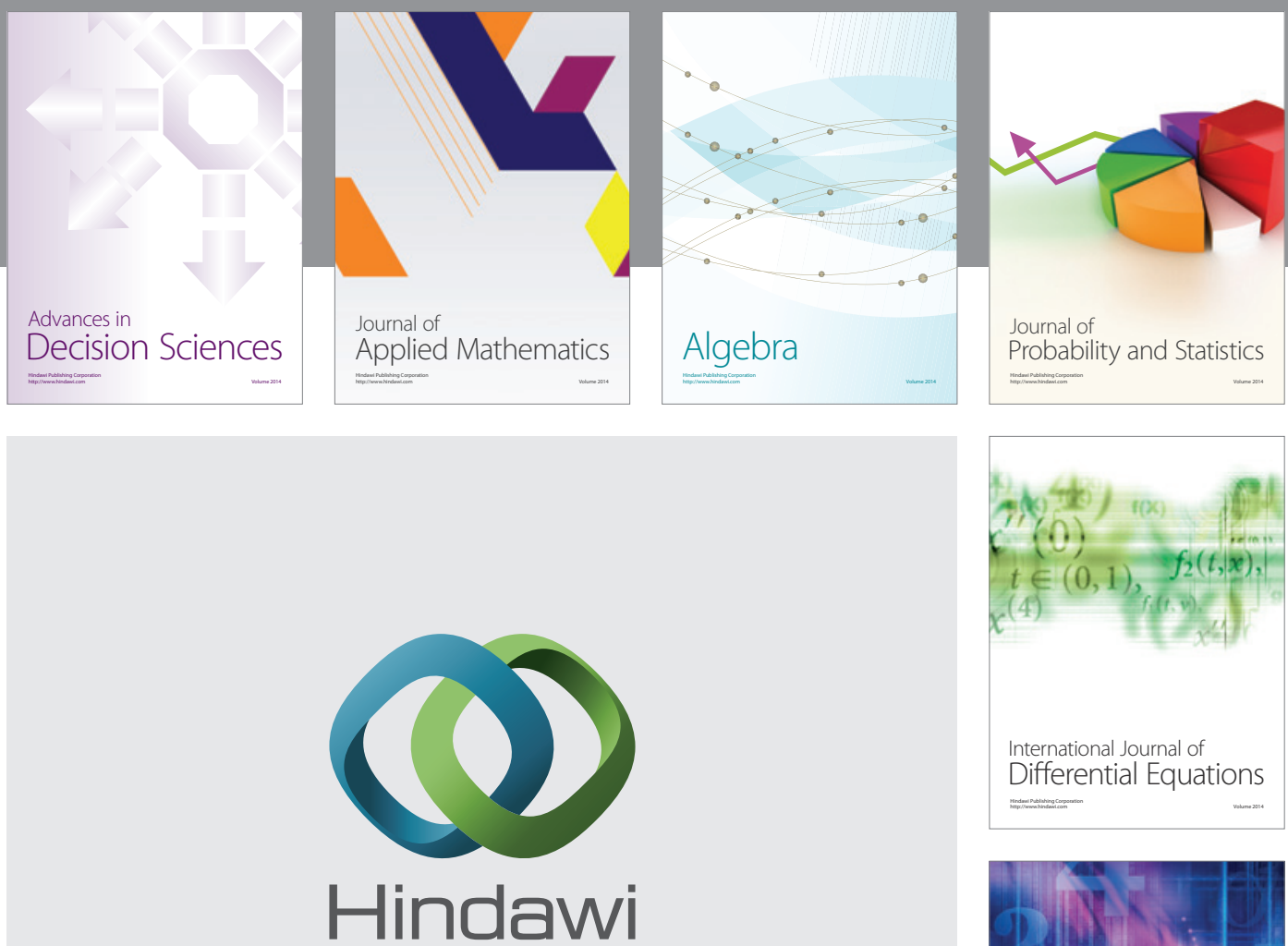

Submit your manuscripts at http://www.hindawi.com
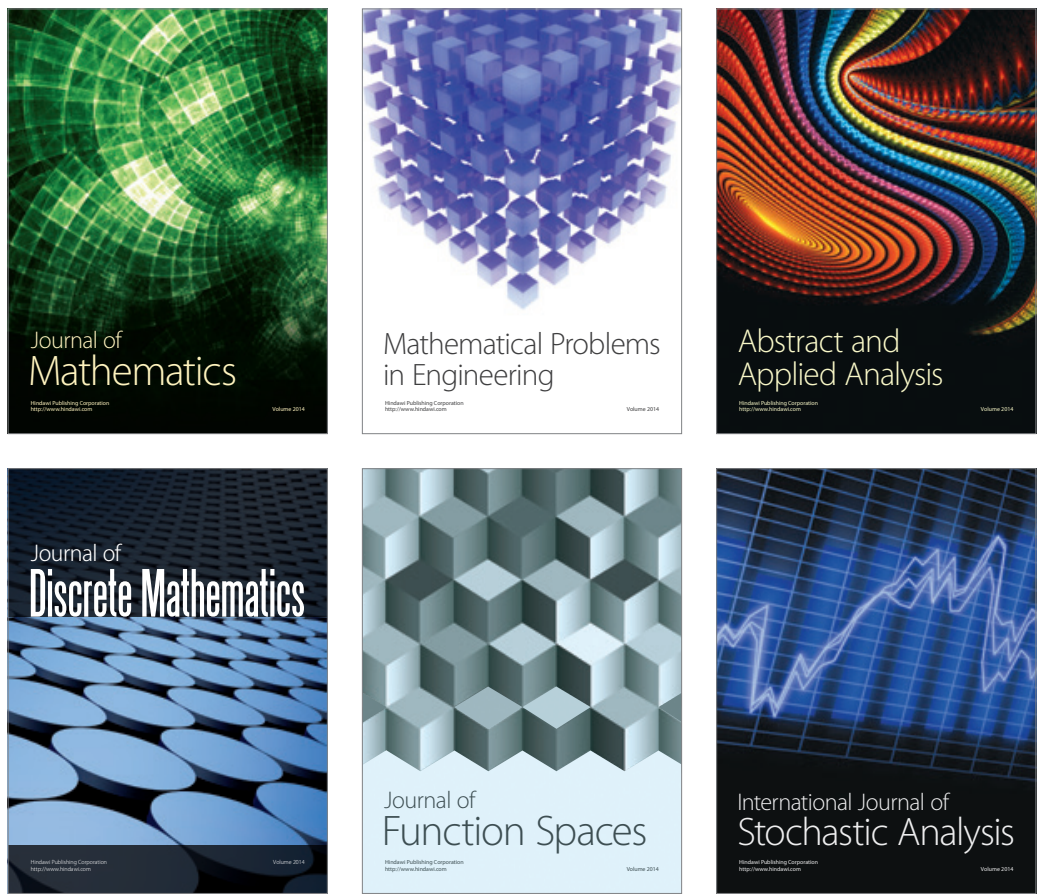

Journal of

Function Spaces

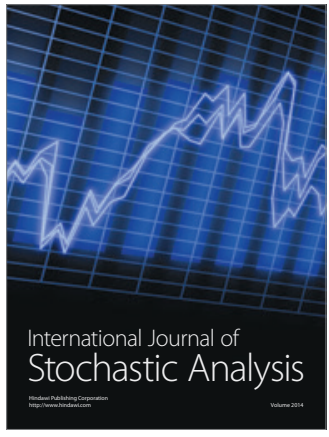

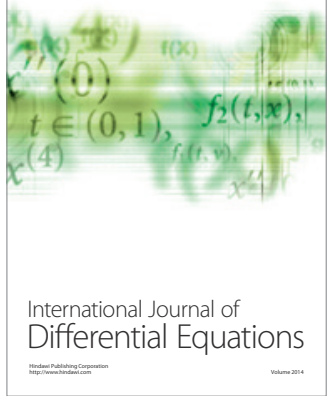
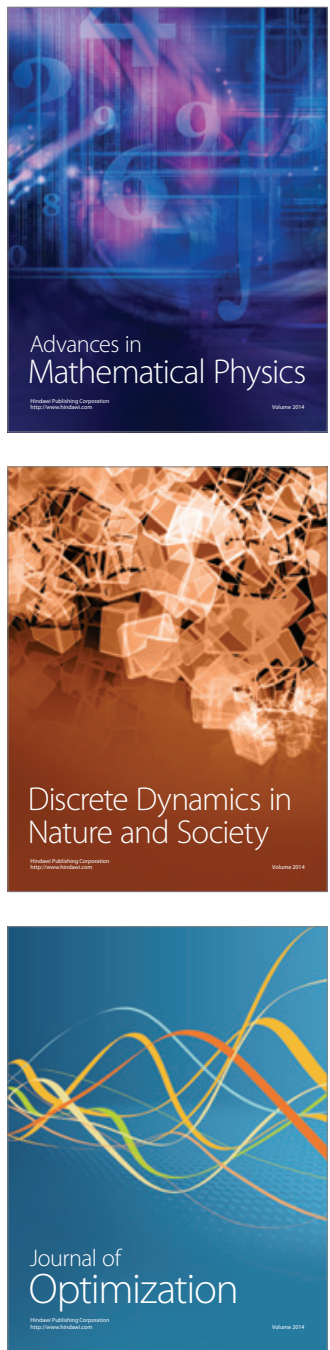